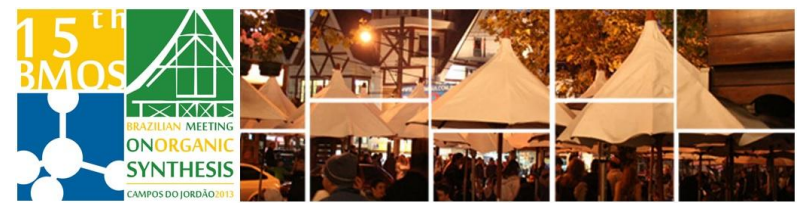

\title{
Ring expansions of $(R)-(-)$-carvone to cycloheptenoid chirons
}

\section{Leandro de C. Alves, André L. Desiderá, Kleber T. de Oliveira and Timothy J. Brocksom*}

\author{
Departmento de Química, Universidade Federal de São Carlos, São Carlos - SP, Brazil \\ *brocksom@terra.com.br.www.lqbo.ufscar.br
}

(R)-(-)-carvone; ring expansion; cycloheptenone, X-ray structure assignment

\section{INTRODUCTION}

In the course of our studies on the synthesis of perhydroazulene terpenes, ${ }^{1}$ we have developed a synthetic route (Scheme 1, Route A) to the cycloheptenone chiron 6 from $(R)-(-)$-carvone (1). Herein we present our corrected structural assignment of $\mathbf{4 a},{ }^{2}$ as confirmed by X-ray analysis, and describe an attractive alternative route towards 6 (Scheme 1, Route B).

\section{RESULTS AND DISCUSSION}

The formation of the TMS-protected cyanohydrins $\mathbf{2 a}$ and $\mathbf{2} \mathbf{b}$ and the Corey-Chaykovsky epoxidation to $\mathbf{3 a}$ and $\mathbf{3 b}$, led to $90: 10$ ratios determined by $\mathrm{GC}$ and NMR analysis of trans:cis nucleophilic addition relative to the isopropenyl group of $(R)-(-)$-carvone (1).

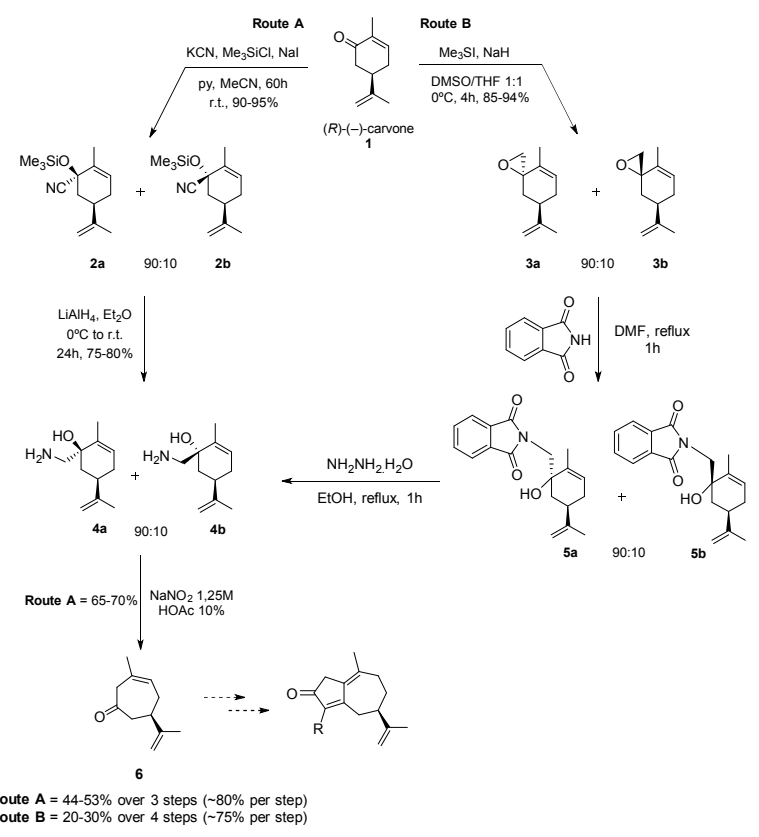

Scheme 1. Synthetic routes from $(R)-(-)$-carvone (1) to the cycloheptenone 6 .

The corrected assignment of the stereochemistry ${ }^{2}$ of 2a was made by X-ray diffraction (Figure 1) and nOe irradiations of the major amino-alcohol $4 a$, obtained by reduction of the cyanohydrin mixture $\mathbf{2 a / 2} \mathbf{b}$.

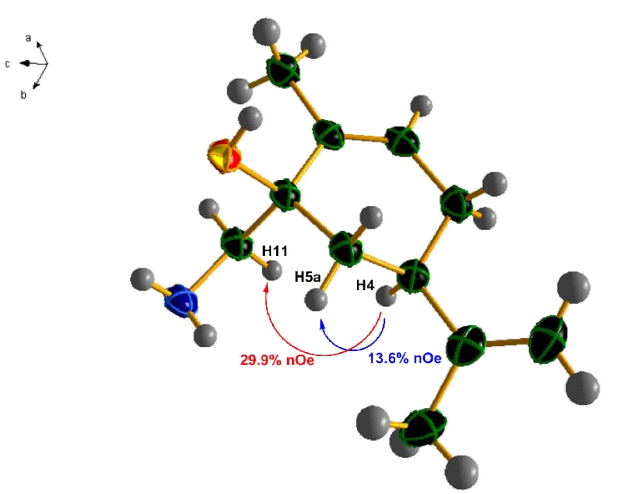

Figure 1. Structure of the major amino-alcohol $4 a$ obtained by X-ray diffraction, and indication of observed nOe. (Ellipsoids shown at 40\% probability level).

Epoxide opening of $\mathbf{3 a} \mathbf{a} \mathbf{3} \mathbf{b}$ (Scheme1, route B) was accomplished by phthalimide in DMF at reflux. Hydrazinolysis of the phthalimido-alcohols $\mathbf{5 a}$ and $5 b$ produced the same amino-alcohols $4 a / 4 b$ obtained in Route A. The last step is the totally regioselective Tiffeneau-Demjanov rearrangement, which leads to the key intermediate cycloheptenone 6.

\section{CONCLUSION}

Addition of the two nucleophiles to (R)-(-)-carvone (1) was determined to be 90:10, in favour of the trans relationship to the isopropenyl group. A new synthetic route to 6 is presented with advantages of scaling up, minimum usage of chromatography, and avoiding the use of cyanide.

\section{ACKNOWLEDGEMENTS}

To FAPESP (2011/13993-2, 2013/06532-4), CAPES and CNPq for financial support and fellowships; Firmenich S.A. for the donation of $(R)-(-)$-carvone. Part of this work was executed at the University of Cambridge, and the authors are grateful to Prof. Steven V. Ley and Dr Sean Newton.

\section{REFERENCES}

${ }^{1}$ Brocksom, T. J., Brocksom, U., Sousa, D. P, Frederico, D. Tetrahedron Asym., 2005, 16, 362. Faria, M. L; Magalhães, R. A.; Silva, F. C.; Matias, L. G. O.; Ceschi, M. A.; Brocksom, U; Brocksom, T. J. Tetrahedron Asym. 2000,11, 4093

2. Alves, L de C.; et al. $14^{\text {th }}$ BMOS, 2011. 